Société d'histoire de la révolution de 1848 et des révolutions du XIXe siècle

49 | 2014

1814-1815. Expériences de la discontinuité

\title{
Hugues MARCHAL [anthologie sous la dir.], Muses et Ptérodactyles. La poésie de la science de Chénier à Rimbaud
}

Paris, Le Seuil, 2013, 658 p. ISBN : 978-2-02-111395-2. 32 euros.

\section{François Jarrige}

\section{(2) OpenEdition}

\section{Journals}

Édition électronique

URL : http://journals.openedition.org/rh19/4766

DOI : $10.4000 /$ rh19.4766

ISSN : $1777-5329$

Éditeur

La Société de 1848

Édition imprimée

Date de publication : 1 décembre 2014

Pagination : 218-220

ISSN : 1265-1354

Référence électronique

François Jarrige, « Hugues MARCHAL [anthologie sous la dir.], Muses et Ptérodactyles. La poésie de la science de Chénier à Rimbaud », Revue d'histoire du XIXe siècle [En ligne], 49 | 2014, mis en ligne le 01 décembre 2014, consulté le 22 septembre 2020. URL : http://journals.openedition.org/rh19/4766 ; DOI : https://doi.org/10.4000/rh19.4766

Ce document a été généré automatiquement le 22 septembre 2020.

Tous droits réservés 


\section{Hugues MARCHAL [anthologie sous la dir.], Muses et Ptérodactyles. La poésie de la science de Chénier à Rimbaud}

Paris, Le Seuil, 2013, 658 p. ISBN : 978-2-02-111395-2. 32 euros.

\section{François Jarrige}

\section{RÉFÉRENCE}

Hugues MARCHAL [anthologie sous la dir.], Muses et Ptérodactyles. La poésie de la science de Chénier à Rimbaud, Paris, Le Seuil, 2013, 658 p. ISBN : 978-2-02-111395-2. 32 euros.

On le sait, le XIX ${ }^{e}$ siècle est une période ambiguë qui marie en permanence le culte de la raison et de la science avec la religiosité et la fascination pour l'occulte. Dans cette grosse et passionnante anthologie consacrée à la poésie scientifique du XIX ${ }^{\mathrm{e}}$ siècle, un collectif d'historiens de la littérature fait ressurgir un genre désormais oublié mais qui exerça en son temps une influence considérable. Entre la Convention et la Belle Époque une masse d'écrits - largement relégués aux oubliettes de l'histoire - a en effet tenté d'associer la science et la poésie. Le premier prix Nobel de littérature en 1901 fut d'ailleurs décerné à Sully Prudhomme, une des principales figures de cette poésie scientifique, et tout au long du siècle des centaines de savants et de poètes, obscurs amateurs ou écrivains reconnus, ce sont essayés à ce genre. À travers 214 textes classés de façon thématique et soigneusement présentés, Muses et Ptérodactyles analyse les fonctions de ce genre, entre vulgarisation et distribution des honneurs, les multiples tensions qui le traversent et les raisons de son discrédit progressif.

La question des relations entre la science et la poésie, entre la précision du savant et le lyrisme du poète, n'a évidemment rien de neuf. Les adeptes du genre se placent d'ailleurs dans une vénérable tradition qui remonte à Lucrèce, Virgile, Ronsard ou 
Voltaire. Mais au XIX ${ }^{\mathrm{e}}$ siècle, alors que les imprimés et le nombre de versificateurs s'accroît, que la "révolution scientifique » s'accélère, le genre se transforme et acquiert un grand dynamisme alors même que la spécialisation des disciplines s'accentue et le fossé entre la science et la poésie commence à se creuser. La force de l'ouvrage est d'aller au-delà des jugements habituels considérant cette littérature comme "des vieilleries de grenier» (p.69) pour discerner sa «modernité » et comprendre sa centralité dans les mutations des champs littéraires et scientifiques du XIX ${ }^{\mathrm{e}}$ siècle. André Chénier au début du siècle comme Maxime du Camp dans les années 1850 invitent leurs contemporains à s'ouvrir aux découvertes fascinantes de la science. Pour eux, la poésie scientifique participe d'un discours d'accompagnement et de légitimation d'une modernité scientifique qui serait bridée et entravée par une société fondamentalement conservatrice : «Quoi, nous sommes le siècle où l'on a découvert des planètes et des mondes, où l'on a trouvé les applications de la vapeur, l'électricité, le gaz, le chloroforme, l'hélice, la photographie, la galvanoplastie, et que sais-je encore? Mille choses admirables, mille fééries incompréhensibles qui permettent à l'homme de vivre vingt fois plus et vingt fois mieux qu'autrefois; quoi, nous avons pris de la terre glaise pour en faire un métal plus beau que l'argent [allusion à l'aluminium récemment isolé], nous touchons à la navigation aérienne, et il faut s'occuper de la guerre de Troie et des Panathénées!» (M. du Camp, Les Chants modernes, 1855, cité p. 75).

3 L'enjeu central est celui du sens du monde moderne de plus en plus façonné par les découvertes de la science. Dans cet univers qui tend au désenchantement, quelle peutêtre la fonction de la poésie? Accompagner la science en la vulgarisant à travers un langage accessible à tous ? Célébrer le scientisme triomphant? Dire de façon inédite la nouveauté inquiétante du monde en gestation? Les réponses ont pu varier selon les auteurs. Mais dans la foulée des Lumières, la poésie scientifique vise d'abord à diffuser les découvertes en adoptant un langage plus évocateur et aimable que l'aridité du discours scientifique. La poésie devait favoriser l'apprentissage et répandre la renommée des découvertes scientifiques, elle devait lever les préjugés populaires en célébrant les saint laïcs de la science, leur souffrance, leur abnégation au service du progrès de l'humanité. À cet égard, la poésie scientifique participe indéniablement d'un langage scientiste qui tend à s'étendre au-delà du monde savant pour coloniser la société et le champ politique.

4 Mais ce genre hybride et foisonnant ne se réduit pas à l'exaltation des grands scientifiques et à la promotion de leur découverte, il relève parfois aussi de la «verve corrosive de la satire » (p. 268). Les effets de la science et de ses réalisations techniques provoquent en effet l'inquiétude et le doute, l'esthétique décadente de la fin du siècle poussera loin le scepticisme, voire la dénonciation, à l'égard d'une science dangereuse et inconsciente de ses effets. D'Alfred de Vigny faisant l'éloge de la lenteur contre le train, ce "dragon mugissant qu'un savant à fait naître ", à Baudelaire pourfendant ce «fanal obscur » qu'est l'idéologie du progrès, la nouvelle idole de la science suscite ses athées et ses incroyants. Le genre s'éteint d'ailleurs largement après 1900, en dépit de quelques cas qui subsistent sous une forme nouvelle, comme en contrebande, et de façon de plus en plus inavouable. Science et poésie s'éloignent irrémédiablement au $\mathrm{XX}^{\mathrm{e}}$ siècle, l'hyperspécialisation et la mathématisation des sciences excluent l'intervention du langage poétique tandis que les poètes affichent de plus en plus leur éloignement voire leur mépris pour la science et pour tout didactisme. Dans ce 
contexte, la poésie scientifique devient un monstre et c'est tout le mérite de cette belle anthologie que de le faire ressurgir et d'en montrer toutes les facettes. 